\title{
Eye care practices among commercial drivers in a developing country
}

\author{
*Chidi-Egboka NC. ${ }^{1}$, Bolarinwa OA. ${ }^{2}$, Awoyemi AO. ${ }^{2}$, Patrick C.
}

\begin{abstract}
Objective: Vision is regarded as the most important source of information during driving. The need for good eye care practices among the commercial drivers therefore cannot be overemphasized. This study aimed to determine the eye care practices of commercial drivers in a developing country and their association with involvement in road traffic crash (RTC).
\end{abstract}

Methods: A cross-sectional descriptive study was carried out among 328 registered commercial drivers in Ilorin metropolis, Kwara State, Nigeria. Multistage random sampling method was used to select the participants while semi-structured, interviewer administered questionnaire was used to obtain information on the socio-demography, eye care practices and involvement in RTC.

Results: Data was analysed using SPSS version 18. The level of significance was set at p-value of less or equal to 0.05 . Most (75.8\%) of the commercial drivers had clear knowledge on good eye care practices. Majority, $79.6 \%$ of them had poor eye care practice. Only one-fifth of the drivers who practice good eye care had been involved in RTC in the last five years $(\mathrm{p}=0.548)$. There was no statistically significant association between good eye care practices and involvement in RTC.

Conclusion: Good eye care practice especially regular eye check at the hospital can help in early detection of poor visual function to enable prompt intervention. The consequences of RTC could be very fatal, it is therefore imperative for commercial drivers to always exhibit good eye care practices bearing in mind the major role of vision in driving.

Keywords: Eye care practice, Commercial drivers, Road traffic crash, Developing country

*Correspondence Author: Chidi-Egboka N.C. Email: ngozzel@yahoo.com or drdeji@yahoo.com or demlol@yahoo.com

'Department of Optometry and Vision Science, University of Ilorin, Ilorin, Nigeria.

${ }^{2}$ Department of Epidemiology and Community Health, University of Ilorin, Ilorin, Nigeria.

${ }^{3}$ Maxi Specialist Eye Clinic, Ikeja, Lagos, Nigeria.

Research Journal of Health Sciences subscribed to terms and conditions of Open Access publication. Articles are distributed under the terms of Creative Commons Licence (CC BY-NC-ND 4.0). (http://creativecommons.org/licences/by-nc-nd/4.0).

http://dx.doi.org/10.4314/rejhs.v5i2.4 


\title{
Pratiques de soins des yeux chez les conducteurs commerciaux d'un pays en développement
}

\author{
*Chidi-Egboka NC. ${ }^{1}$, Bolarinwa OA. ${ }^{2}$, Awoyemi AO. ${ }^{2}$, Patrick C. ${ }^{3}$ \\ Resume \\ Objectif: la vision est considérée comme la source d'information la plus importante pendant la conduite. \\ Le besoin de bonnes pratiques de soins oculaires chez les conducteurs commerciaux ne peut donc pas être \\ trop souligné. Cette étude visait à déterminer les pratiques de soins oculaires des conducteurs \\ commerciaux dans un pays en développement et leur association avec la participation à un accident du \\ trafic routier $(\mathrm{RTC})$.
}

Méthodes: Une étude descriptive transversale a été menée auprès de 328 conducteurs commerciaux enregistrés dans la métropole Ilorin, Kwara State, Nigeria. La méthode d'échantillonnage aléatoire à plusieurs étapes a été utilisée pour sélectionner les participants en semi-structuré, le questionnaire administré par l'intervieweur a été utilisé pour obtenir des informations sur la sociodémographie, les pratiques de soins oculaires et la participation à la RTC.

Résultats: Les données ont été analysées à l'aide de la version 18 de SPSS. Le niveau d'importance a été fixé à une valeur $p$ inférieure ou égale à 0,05 . La plupart $(75,8 \%)$ des conducteurs commerciaux avaient une connaissance claire des bonnes pratiques de soins oculaires. En majorité, 79,6\% d'entre eux avaient une mauvaise pratique des soins oculaires. Seulement un cinquième des conducteurs qui pratiquent de bons soins de l'oeil ont été impliqués dans RTC au cours des cinq dernières années $(p=0.548)$. Il n'y avait aucune association statistiquement significative entre les bonnes pratiques de soins oculaires et la participation à la RTC.

Conclusion: Une bonne pratique des soins oculaires, en particulier un contrôle oculaire régulier à l'hôpital, peut aider à détecter rapidement une fonction visuelle médiocre pour permettre une intervention rapide. Les conséquences de RTC pourraient être très fatales, il est donc impératif que les conducteurs commerciaux présentent toujours de bonnes pratiques de soins oculaires en tenant compte du rôle majeur de la vision dans la conduite.

Mots-clés: pratique des soins oculaires, conducteurs commerciaux, accident routier, pays en développement

* Correspondance Auteur: Chidi-Egboka N.C. Email: ngozzel@yahoo.com or drdeji@yahoo.com or demlol@yahoo.com

${ }^{1}$ Department of Optometry and Vision Science, University of Ilorin, Ilorin, Nigeria.

${ }^{2}$ Department of Epidemiology and Community Health, University of Ilorin, Ilorin, Nigeria.

${ }^{3}$ Maxi Specialist Eye Clinic, Ikeja, Lagos, Nigeria. 


\section{INTRODUCTION}

Commercial drivers are considered to be very important, especially in a developing country such as Nigeria, where majority of the people go on public transport. Most drivers with inadequate vision for driving are often not aware of it because they have never been exposed to any form of eye test (1). Central vision or Visual acuity (VA) which is the finest spatial detail is used to discern detail, identify, and/or recognize what the driver is looking at during driving (2). Certain visual conditions may impair VA, thus impair individual's ability to drive safely. Visual acuity impaired by one or more vision conditions can result in the driver failing to read signs and/or recognize hazards in a timely manner (2).

Being a driver has a profound impact on health and well-being. There is widespread agreement that vision standards for driver licensure need to be evidence-based so as not to unfairly prohibit individuals from driving who have the visual skills necessary to do so, in spite of being visually impaired (3). Driving cessation, regardless of whether it is voluntary or involuntary (example, license revocation), can have a number of adverse consequences such as decreased health-related quality of life, increased likelihood of depression \& social isolation and reduced access to healthcare services (3). Comprehensive routine eye care and maintaining good eye care practice is an important part of the health care process that should be adopted by drivers (4). It is an important practice regardless of your age, occupation or your physical health (5).

Comprehensive eye exam often reveals much more than just to determine the prescription for glasses or contact lenses (5). An eye examination can reveal signs of many systemic diseases, including diabetes and high blood pressure which can cause visual impairment if not properly managed. It will also reveal some eye conditions such as glaucoma which usually has no symptoms but can lead to irreversible loss of sight $(5,6)$. Routine yearly visual examination is definitely recommended at 40 years of age and above (6). This is because that is the time when early signs of disease and changes in vision are mostly common. Incidentally, most research has revealed age 50 years and below as the mean age of commercial drivers, so this explains how important routine eye check is for drivers (7). Unfortunately, practice of routine eye check is rare in developing countries where the level of illiteracy and poverty is averagely high $(4,8)$.
Majority of residents in such countries are usually more engaged in meeting up with daily needs and barely remember such routine practice.

Drivers are critical to road safety (9). Commercial drivers are responsible for their safety as well as the safety of all the people who share the road with them (9). The medical precautions they take such as good eye care practice, to maintain eligibility to drive confirms their ability to safely perform the demanding job of commercial vehicle driving and keeping our roads safe. The role of commercial drivers in motor vehicle related injuries have been reported in Ghana (10). The study revealed that majority of the commercial drivers had good knowledge on the importance of vision in relation to road traffic crashes (RTCs), only a few had ever had any eye examination. The study concluded that commercial vehicle drivers are an important group to target in road safety programs.

During the last two decades there has been a burst of research activity focused on the role of vision in driving, much of which has been centred on what types and degrees of vision impairment hamper driver safety and performance (3). Research has addressed the role of vision in driver safety (motor vehicle collision involvement) and in driver performance (both on-road and using interactive simulators in the laboratory) (3) but not much has been revealed about knowledge of eye care and eye care practices among these drivers which are factors that can influence their vision.

This study was therefore aimed at determining the eye care practices of commercial drivers in Nigeria, a developing country. The assessment of the drivers' knowledge on eye care, eye care practices and past ocular history with regards to driving safety was evaluated.

\section{MATERIALS AND METHODS}

This cross-sectional descriptive study was carried out in Ilorin, the capital city of Kwara State, Nigeria, a developing country in Africa. Commercial drivers who are registered with National Union of Road Transport Workers (NURTW) and Road Transport Employers Association of Nigeria (RTEAN), Kwara Express and private motor parks in Ilorin metropolis participated in the study. These drivers were those who drive four wheel vehicles and convey passengers both intra and intercity. Approval for the study was obtained from the Department of Epidemiology and Community Health of the University. Informed consent was obtained from 
each of the selected participants after comprehensive information detailing study protocol was given to them. The research followed the tenets of the declaration of Helsinki. Registered 4,729 commercial drivers in private and public motor parks formed the sampling frame for this study. Three hundred and twenty eight drivers were calculated and included in this study using Fischer's formula and adjustment for population of less than 10,000 . The sampling technique was multistage. At stage one, 7 motor parks were selected randomly by balloting without replacement from the list of all the motor parks in Ilorin while at stage 2 registered drivers were proportionately allocated and then randomly selected using table of random numbers. Interviewer administered semistructured questionnaires were completed by trained research assistants for the purpose of data collection in the study. Six research assistants were trained over two days on questionnaire administration. The questionnaire was pre-tested among commercial drivers in Offa, Kwara State. The questionnaire elicited questions to obtain information concerning socio-demographical data, driving history including history of involvement in road traffic crash (RTC), ocular history, knowledge on eye care and eye care practices among respondents. Some of the major assessment tools for knowledge on eye care and eye care practice used were knowledge on the importance of eye to human, dangers associated with poor vision, regular/routine eye check at the hospital, practice of self-medication, compliance with doctor's prescription and various local/traditional eye care practices.

Data analysis was done using statistical package for social sciences (SPSS) version 18.0, and presented as charts, tables, and frequency cross tabulations. Appropriate test of significance (chi-square test) was used to test statistics and the level of significance was predetermined at $\mathrm{p}$ value of equal to or less than 0.05 at $95 \%$ confidence level. A Likert scale was used to categorize the respondents' driving safety. The scoring of their driving safety was converted to percentage by proportion such that the minimum score was zero and highest score was 100 percent. The grading of the scores was as follows; 0 $44.9 \%$ - poor driving safety, $45-64.9 \%$ - fair driving safety and $65-100 \%$ - good driving safety.

A major limitation of the result of this study was the unavailability of a state crash record of individual drivers to validate the veracity of each respondent's report. The study relied on self-reported road traffic crashes by the respondents. One would expect some tendency to under-report crashes due to fear of unknown/legal implications.

\section{RESULTS}

Three hundred and twenty-eight consenting commercial drivers participated in the study. The age of the respondents ranged from 20 to 70years with a mean age of $46 \pm 10.13$ years. Majority $209(63.7 \%)$ of them were in the age group $40-59$ years. (Table 1 )

The respondents were all male. Less than half of the respondents $146(44.2 \%)$ had primary education while $56(17.1 \%)$ had no formal education. Almost three quarter $240(73.2 \%)$ of the respondents had no other occupation other than driving. Majority 318 (97\%) of the respondents were married and their ethnicity were mainly (93.6\%) Yorubas.

Majority of the respondents 321 (97.9\%) possessed a driver's license. More than two-third had a driving test conducted before obtaining license. Majority 314 (97.8\%) renewed their license on expiration. Less than one-third 89 (27.7\%) had eye test before obtaining license while $49.4 \%$ of them had a repeated eye test during license renewal.

About one-fifth of the respondents 64 $(19.5 \%)$ had been involved in RTC in the past 5 years. More than half $(62.5 \%)$ of the road traffic crashes were without any injury sustained. This study revealed vehicular factor (which includes poor vehicle maintenance, tyre blowouts, poor lights, un-roadworthy vehicles, brake failure and broken-down vehicles on the road without adequate warning) as the major (76.6\%) cause of RTC. (Table 2)

Almost all the respondents 326 (99.4\%) claimed to have good peripheral visual field. Majority of the respondents $320(97.6 \%)$ claimed to have good vision detection ability. A large proportion $(98.2 \%)$ claimed good ability to recognize road signs and see traffic light at least 6 metres away while driving. (Table 3 )

All the respondents claimed to have clear knowledge on the importance of eye to human. Majority of the respondents 313(95.4\%) have good knowledge on dangers associated with poor vision. Majority of the respondents have good knowledge about good eye care practices. (Table 3)

Among all the listed respondents' eye care practices, the least is maintenance of regular eye 
check at the hospital. An average of 324 (98.5\%) of the respondents claimed they do not practice traditional eye care. (Table 4)

Majority of the respondents 247 (75.3\%) have never had a voluntary eye check-up. The respondents' reason for irregular eye check-up was mainly due to absence of eye problem 201 $(81.4 \%)$ followed by lack of awareness 27 (10.9\%). (Table 4)

Good eye sight and the need for eye medication $(28.4 \%$ each) were the highest in frequency on the outcome of the respondents' eye check-up in the time past. More than half out of the 23 respondents $14(60.9 \%)$ who were told they needed glasses, got the glasses. (Table 5)

Likert scale was used to score the respondents' eye care practice. Majority, 79.6\% of respondents had poor eye care practice, $19.8 \%$ had fair eye care practice while only $0.6 \%$ respondents had good eye care practice. (Figure 1)

Only one-fifth of the respondents who practice good eye care had been involved in RTC in the last five years. There was no statistically significant association between good eye care practices and involvement in RTC. (Table 6)

\section{DISCUSSION}

The study revealed that majority 209 (63.7\%) falls within the age group 40 - 59years, this is similar to past studies $(1,7,11,12,13)$.

More than two-thirds $268(83.5 \%)$ of the drivers in this study passed through a driving test at first licensing but only a very few $89(27.7 \%)$ had their eyes tested at first licensing and much fewer $44(13.7 \%)$ during license renewal. This is a clear indication that some drivers with poor visual function may be certified as fit for driving even when they are deficient. This poses a very big risk to RTCs and demands the need to address this through an aggressive public awareness campaign, education and enforcement by concerned agencies.

The European Union (EU) has recently published Directives in order to standardise driving licences and harmonise requirements. Currently the visual requirements to obtain a driving licence differ substantially across Member States and non EU Countries. A number of countries in Europe (including EU Member States) are not assessing drivers to the minimum recommendations contained within the EU legislation. The majority recognise the importance of good vision for safe driving and go above the basic requirements from the Directives, for example by introducing systematic assessment of vision during the driving career, and this good example should be followed by all (13). The minimum vision standard accepted by EU for drivers of cars and motorcycles is to have a binocular visual acuity of at least $6 / 12$ with or without correction, and binocular visual field standards are limited to no less than $120^{\circ}(13)$. For monocular vision, applicants must have a corrected or uncorrected visual acuity of at least 6/9. Driver's licenses may be issued or renewed provided that the applicant undergoes prelicensing eye examinations. In Nigeria, Federal Road Safety Corp (FRSC) standard for the issuance of drivers' licence requires that VA should be better or equal to $6 / 9$ in the better eye and $6 / 24$ in the second eye which is rarely complied with $(1,14)$. In most occasions licenses are being issued without any measure of VA in Nigeria $(1,7)$.

In most published studies the statistical correlations between vision and traffic crashes are weak. The recent publication on assessing and counselling older drivers points explicitly to the interactions of various deficits, where vision is only one of the relevant parameters, while visual acuity is only one parameter of vision (15). It must be remembered that the decisive factor is not what drivers see, but how they react to what is seen. Various restrictions/limitations could be imposed on the drivers based on their visual status, including the following (15).

1. Limitation to daylight driving

2. Restriction to familiar areas

3. Speed limitation

4. No highway driving

5. Requirement of more frequent testing based on the prognosis of the condition.

The health check-up history of the respondents showed that they go more $(50.9 \%)$ for medical check-up than they do for eye checkup $(24.7 \%)$. Their reason for not going for regular eye check-up is mainly ( $81.4 \%$ ) due to absence of eye complaints. There is need for increased awareness campaign to the relevant stakeholders on the importance of routine eye check. The benefits of routine eye check cannot be overemphasized going by the alarming rate of visual impairment in Nigeria $(16,17)$.In a study to determine the prevalence of blindness and visual impairment among adults aged $\geq 40$ years in Nigeria. It is estimated that 4.25 million adults aged $\geq 40$ years have moderate to severe visual impairment or blindness (17).

As part of feed-back from the 
respondents who have had eye check-up, about $28.4 \%$ respondents were told they needed glasses. A large proportion of them $(60.9 \%)$ got the glasses and about $50.0 \%$ of them use it for driving. The drivers gave their reasons for not driving with their glasses out of which $71.4 \%$ of them said their glasses were meant for reading only.

Among the good eye care practices of the respondents, not playing with sharp objects topped the list $(89.9 \%)$, followed by avoidance of self-medication $(78.4 \%)$ but the least was practice of regular eye check at the hospital (32.3\%). Using Likert scale to categorize the respondents' eye care practices, the study revealed that majority $(79.6 \%)$ of them practice poor eye care. Drinking of herbal concussion was the highest (3.7\%) among the traditional eye care practices followed by washing the eye with urine, putting breast milk in the eye, visiting an herbalist or a Mallam for eye care (example, couching). Some of these traditional eye care practices often cause serious/irreversible damage to eye health (18).

Visit to Mallam for cataract surgery has been found to contribute a high prevalence in the rate of visual loss among the age group studied in Nigeria (16). There is obvious need to stress on the importance of regular/routine eye check because through that, any visual deficiency can be diagnosed at an early stage and be treated accordingly (19).

A study in Ghana assessed the knowledge and self-reported practices of commercial drivers (10). There were some important deficits in the drivers' knowledge and in their self-reported practices. Despite indicating that good vision is important, few had ever had their vision checked. There seemed to be the belief that only drivers with very poor vision (for example cataracts) would be at increased risk for road traffic crashes. There did not seem to be an understanding that most vision problems could be corrected. This calls for serious concern because poor eye care practice is very dangerous and some visual impairment as a result could lead to irreversible loss of vision.

The rate of involvement in road traffic crash in the past 5 years found in this study was based on self-reported crashes by the drivers. The major cause of RTC (vehicular factor) as reported in this study opposes several other reports from previous studies that revealed human factor (visual function impairment, driver fatigue, poor knowledge of road signs and regulations, illiteracy, health problems, excessive speeding, drug abuse, and over-confidence while at the steering wheel) as the principal cause of RTC $(20,21)$. In Nigeria, statistics indicate that over $90 \%$ of the RTCs situations can be attributed to driver error (22). The state RTC record obtained from FRSC, Kwara State Command for the year 2010 to 2013 also showed that the major cause of RTC was human factor and speed violation stands out as the major factor $(26.4 \%)$, followed by dangerous driving $(21.0 \%)$, loss of control $(12.6 \%)$ and various other factors in lower percentages. The reason for this deviation from the widely reported trend could probably be explained by increased awareness on the dangers of human factor errors during driving from past studies. The vehicular factor identified in this study could be explained by the poor state of economy due to global economic meltdown and other associated factors such as unemployment, poverty and so on, hence influencing poor vehicle maintenance/management (23).

Possession of driving license was not in any way associated with involvement in RTC $(3,7)$. The reason is quite simple, just as has been mentioned above, almost all the drivers were never tested for visual impairment before issuance of license or during renewal.

This study therefore revealed no association between good eye care practices and involvement in road traffic crash which is similar to a study on "Risk factors for Road traffic Accidents among Drivers of Public Institution in Ibadan Nigeria" (24). More of the respondents who practice lack of compliance with Doctor's treatment were involved in road traffic crash followed by those who practice eye surgeries/washing with Mallam (couching). Couching is a practice known to be synonymous with cataract extraction which is a common eye problem of the elderly. A study (3) examined the effect of cataract on driving and found that drivers with cataract were 2.5 times more likely to have had a history of involvement in RTC compared to their counterparts without cataract.

An increased risk of RTC amongst visually impaired drivers was observed in the study by Bekibele et al., suggesting an important role for poor vision in RTC causation. The study also observed an increase in the prevalence of RTC among older aged drivers. This may be related to increasing visual impairment with old age (24). Davidson in his examination of the interrelationship between British drivers' visual abilities, age and RTC histories found strongest positive association between RTC variables and visual disabilities, among older drivers (3). This pattern of result (i.e., significant yet weak 
associations) has been observed in other studies (3). As people age, visual functions deteriorate due to increase in the incidence of age-related ocular conditions such as cataract, macular degeneration, open-angle glaucoma, and diabetic retinopathy $(5,6)$. This study revealed that majority of commercial drivers fall within age group known to be more prone to visual function impairment $(6,7)$. Thus there are 2 accident peaks in the life of an individual, in the young when one is prone to risk taking behaviour, poor eye care practices and in the elderly when visual impairment prevents adequate visual function. It is therefore important to target both groups in promoting awareness for importance of routine medical eye check-up/adherence to follow-up care and planning intervention programs to curb RTCs.

\section{CONCLUSION}

Many drivers do not notice a gradual change in their visual status (whether visual acuity, visual field or other visual functions), and can therefore be unaware that they fall below the required standard for driving. Studies have shown a widespread lack of awareness about the current visual standards and the legal implications of driving with poor vision among drivers.

This study revealed that greater percentage of the respondents has poor eye care practice $(79.6 \%)$. However, there was no statistically significant association between practice of good eye care and the rate of involvement in road traffic crash.

Eye care practice assessment tools can serve as valuable instrument in raising public/driver awareness of abilities and problems, but they cannot act as a definitive measure of driving competence, and should not be promoted as such. The limitations and benefits of current tools should be acknowledged, so that they can be used appropriately. However, there are suggested regular examination guidelines for good eye care. ${ }^{(25)}$ There is need for availability of simple screening devices for quick assessment by skilled personnel in the department responsible for issuing motor vehicle licenses due to the importance of driving with good vision.

Acknowledgement: Sincere thanks to all the subjects who participated in the study and made it a success, to the managers of the motor parks used and to the research committee, department of Epidemiology \& Community health, University of Ilorin.
Conflict of interest: The authors declare no conflict of interest.

\section{REFERENCES}

1. Adekoya BJ, Owoeye JF, Adepoju FG, Ajaiyeoba A. Visual Function Survey of Commercial intercity Vehicle Drivers in Ilorin Nigeria. Can J Ophthalmol.2009; 44(3):261-4

2. State of California, Department of Motor Vehicles. Vision Conditions. 2016. Available at www.dmv.ca.gov

3. Owsley C, Mcgwin G. Vision and Driving. Vision Res. 2010; 50(23): 2348-2361.

4. Onakpoya $\mathrm{OH}$, Adeoye AO, Akinsola FB, Adegbehingbe BO.Prevalence of blindness and visual impairment in Atakunmosa West Local Government area of southwestern Nigeria. Tanzan Health Res Bull. 2007; 9:126-31

5. Heiting G, Palombi J. Why Are Eye Exams Important? 2016. Available at www.allaboutvision.com

6. NHS Choices. Why Are Eye Tests Important. 2014. Available at www.nhs.uk/chq/pages/2554

7. Adekoya BJ, Adekoya AO, Adepoju FG, Owoeye JFA. Driving under influence among long distance commercial drivers in Ilorin, Nigeria. Int. J Biol Med Res 2011; 2(4):870-873

8. Adegbehingbe BO, Majengbasan TO.Ocular health status of rural dwellers in south-western Nigeria. Aust J Rural Health. 2007; 15:269-72.

9. Federal Motor Carrier Safety Administration. Driver Medical Fitness for Duty. 2016. Available at www.fmcsa.dot.gov

10. Mock C, Amegashie J, Darteh K. Role of commercial drivers in motor vehicle related injuries in Ghana. Inj Prev. 1999;5:268-271.

11. Rubin GS, Ng ES, Bandeen-Roche K, Keyl PM, Freeman EE, West SK. A prospective, population based study of the role of visual impairment in motor vehicle crashes among older drivers: the SEE study. Invest Opthalmol Vis Sci. 2007; 48:1483-91

12. Silveira S, Jolly N, Heard R, Clunas NJ, Kay L. Current licensing authority standards for peripheral visual field and safe on -road senior aged automobile driving performance. Clin Experiment Opthalmol. 2007; 35:612-20.

13. ECOO, EURO, EUROMCONTACT. Report on Driver vision screening in Europe. 2011. Available at www.eco.info/wpcontent/uploads/2012/OD/

14. Chidoka OB. Activating the United Nation's Decade of Action on Road Safety in Nigeria.

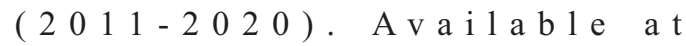
http://www.frsc.gov.ng./decadefaction2010.

15. Road Safety. A Public Health Issues. WHO 2011. 
Available at http//www.who.int/road safety/apublic/health/issue.

16. Sight Savers International, $\mathrm{CBM}$ and International Centre for Eye Health. The Nigerian national blindness and visual impairment survey.(2005 - 2007); pp.2-23. A v a i l a b l e a t www.pbunion.org/countriessurveyresults/Niger ia/Nigeria_survey summary-report.

17. Kyari F, Gudlavalleti MVS, Sivsubramaniam S, Gilbert CE, Abdull MM, Entekume G, Foster A, The Nigeria National Blindness and Visual Impairment in Nigeria: The National Blindness and Visual Impairment Survey. Invest Opthalmol Vis Sci. 2009; 50:2033-2039

18. Wilkinson JT, Fraundfelder FW. Use of Herbal Medicines and Nutritional Supplements in Ocula Disorders: An Evidence Based Review. Drugs. 2011;71(18):2421-34

19. Robb G, Sultana S, Ameratunga S, Jackson R. A Systematic Review of Epidemiological Studies investigating Risk Factors for Work-related Traffic Crashes and Injuries. Inj Prev. 2008; 14: 51-58.

20. Sumaila AF. Road crashes trends and safety management in Nigeria. JGRP. 2013; 6(3):5362.

21. Agbonkhese O, Yisa GL, Agbonkhese EG, Akanbi DO, Aka EO, Mondigha EB. Road Traffic Accidents in Nigeria: Causes and Preventive Measures. CER. ISSN 2224-5790 (Paper) ISSN 2225-0514 (Online),2013;(3):13

22. World Health Organization. Global status report on road safety 2015. Available at

23. Abimbola AO. Impact of the global financial crisis on the Nigerian economy. 2013 Available atwww.proshareng.com/news/21539.

24. Bekibele CO, Fawole OI, Bangboye AE, Adekunle LV, Ajayi R, Baiyeroju AM.Risk factors for Road traffic Accidents among Drivers of Public Institution in Ibadan Nigeria. Afr $J$ Health Sci. 2007; 14:137-142.

25. Oladehinde MK, Adeoye AO, Adegbehinde BO,Onakoya AO.Visual functions of commercial drivers in relation to Road accidents in Nigeria. Indian J Occup Environ Med. 2007; 11:71-5. 
Table 1: Respondents' Sociodemography and Involvement in of Road Traffic Crash

\begin{tabular}{|c|c|c|c|c|}
\hline \multicolumn{2}{|c|}{ Sociodemography } & \multicolumn{2}{|c|}{ Involvement in RTC } & \multirow{2}{*}{ Total } \\
\hline & & Yes & No & \\
\hline \multirow[t]{5}{*}{ Age group } & $20-29$ & 3 & 12 & 15 \\
\hline & $30-39$ & 16 & 54 & 70 \\
\hline & $40-49$ & 20 & 74 & 94 \\
\hline & $50-59$ & 22 & 93 & 115 \\
\hline & $>=60$ & 3 & 31 & 34 \\
\hline \multirow[t]{5}{*}{ Education } & No education & 8 & 48 & 56 \\
\hline & Primary & 28 & 117 & 145 \\
\hline & Secondary & 17 & 56 & 73 \\
\hline & Tertiary & 3 & 17 & 20 \\
\hline & Others & 8 & 26 & 34 \\
\hline
\end{tabular}

Table 2: Road Traffic Crash History among Respondents

\begin{tabular}{lll}
\hline Variables & Frequency & Percentage \\
\hline Involvement in Road Traffic Crash in the & \\
Past (N=328) & 64 & \\
Yes & 264 & 19.5 \\
No & & 80.5 \\
& & \\
Number of Road Traffic Crash in the Past & \\
$\mathbf{5}$ Years (n=64) & 32 & 50.0 \\
None & 25 & 39.1 \\
Once & 6 & 9.4 \\
Twice & 1 & 1.5 \\
Thrice & & \\
& 40 & 62.5 \\
Seriousness of the Crash (n=64) & 14 & 21.9 \\
No injury & 10 & 15.6 \\
Mild to serious injury & & \\
Fatal injury & 4 & 6.3 \\
& 49 & 76.6 \\
Cause of crash (n=64) & 8 & 12.5 \\
Road factor & 3 & 4.6 \\
Vehicular factor & & \\
Human factor & & \\
Animal &
\end{tabular}


Table 3: Respondents' Knowledge on Vision and Eye Care Practice

\begin{tabular}{|c|c|c|}
\hline $\begin{array}{l}\text { Knowledge of Difficulties and Dangers } \\
\text { Associated with Poor Vision }\end{array}$ & Yes $(\%)$ & No (\%) \\
\hline Difficulty in seeing far objects & $309(94.2)$ & $19(5.8)$ \\
\hline Difficulty in seeing near objects & $306(93.3)$ & $22(6.7)$ \\
\hline Loss of interest in driving & $304(92.7)$ & $24(7.3)$ \\
\hline Suicidal thoughts & $292(89.0)$ & $36(11.0)$ \\
\hline Difficult in reading road signs & $306(93.3)$ & $22(6.7)$ \\
\hline $\begin{array}{l}\text { Difficulty seeing objects on both sides of the } \\
\text { road }\end{array}$ & $307(93.6)$ & $21(6.4)$ \\
\hline Difficulty in seeing colours & $307(93.6)$ & $21(6.4)$ \\
\hline Increase risk of falls and fractures & $313(95.4)$ & $15(4.6)$ \\
\hline Increase risk of road traffic injuries & $311(94.8)$ & $17(5.2)$ \\
\hline Knowledge on Good Eye Care Practices & Yes $(\%)$ & No $(\%)$ \\
\hline Annual routine eye check & $260(79.3)$ & $68(20.7)$ \\
\hline Avoidance of self-medication & $290(88.4)$ & $37(11.3)$ \\
\hline Compliance with doctors treatment & $217(66.2)$ & $111(33.8)$ \\
\hline No fear of eye surgery & $220(67.1)$ & $108(32.9)$ \\
\hline Wearing of sun protective spectacles & $220(67.1)$ & $108(32.9)$ \\
\hline Wearing of spectacle prescription & $285(86.9)$ & $43(13.1)$ \\
\hline
\end{tabular}

Table 4: Respondents' Eye Care Practices $(\mathrm{N}=328)$

\begin{tabular}{lll}
\hline Eye Care Practices & Yes (\%) & No (\%) \\
\hline Preventive Eye Care Practices & & \\
Regular eye check at the Hospital & $106(32.3)$ & $222(67.7)$ \\
Avoidance of self-medication & $257(78.4)$ & $71(21.6)$ \\
Compliance with doctors treatment & $181(55.2)$ & $147(44.8)$ \\
Wearing of sun protective spectacles & $143(43.6)$ & $185(56.4)$ \\
Not playing with sharp objects & $295(89.9)$ & $33(10.1)$ \\
& & \\
Traditional Eye Care Practices & $6(1.8)$ & $322(98.2)$ \\
Washing the eye with Urine & $5(1.5)$ & $323(98.5)$ \\
Putting breast milk into the eye & $12(3.7)$ & $316(96.3)$ \\
Drinking of herbal concussion & $1(0.3)$ & $327(99.7)$ \\
Using battery acid to wash the eye & $1(0.3)$ & $327(99.7)$ \\
Washing the eye with coconut water & $2(0.6)$ & $326(99.4)$ \\
Visiting an Herbalist or a Mallam for eye & & \\
care & & \\
& & Percentage \\
Reasons for Irregular Eye Check-Up & Frequency & 81.4 \\
No eye problems & 201 & 3.2 \\
No money & 8 & 10.9 \\
Not aware & 27 & 0.4 \\
Not interested & 1 & 4.1 \\
No time & 10 & 100.0 \\
Total & 247 & \\
\hline
\end{tabular}


Table 5: Respondents' Past Eye Check-Up History

\begin{tabular}{|c|c|c|}
\hline Respondents' Past Eye Check-Up History & Frequency & Percentage \\
\hline Good eye sight & 23 & 28.4 \\
\hline Need eye glasses & 23 & 28.4 \\
\hline Need eye medication & 22 & 27.2 \\
\hline Regular eye check & 10 & 12.3 \\
\hline Need surgery & 3 & 3.7 \\
\hline Total & 81 & 100 \\
\hline \multicolumn{3}{|l|}{ Collected glasses } \\
\hline Yes & 14 & 60.9 \\
\hline No & 9 & 39.1 \\
\hline Total & 23 & 100.0 \\
\hline \multicolumn{3}{|l|}{ Reasons for not getting glasses } \\
\hline No interest & 4 & 44.4 \\
\hline No money & 5 & 55.6 \\
\hline Total & 9 & 100.0 \\
\hline \multicolumn{3}{|l|}{ Wear glasses when driving } \\
\hline Yes & 6 & 42.9 \\
\hline No & 8 & 57.1 \\
\hline Total & 14 & 100.0 \\
\hline \multicolumn{3}{|l|}{ Reasons for not driving with glasses } \\
\hline No interest & 1 & 12.5 \\
\hline Reading only & 6 & 75.0 \\
\hline Not comfortable & 1 & 12.5 \\
\hline Total & 8 & 100.0 \\
\hline
\end{tabular}


Table 6: Association between Good Eye Care Practices and Involvement in Road Traffic Crash in the last 5 years

\begin{tabular}{|c|c|c|c|c|c|}
\hline \multirow[b]{2}{*}{$\begin{array}{l}\text { Good Eye } \\
\text { Practices }\end{array}$} & \multicolumn{5}{|c|}{$\begin{array}{l}\text { Involvement in Road Traffic } \\
\text { Crash in the last } 5 \text { years }\end{array}$} \\
\hline & Yes $(\%)$ & No $(\%)$ & Total(\%) & $\chi^{2}$ & $\mathbf{P}$ \\
\hline \multicolumn{6}{|l|}{ Annual Eye check-up } \\
\hline Yes & $51(19.6)$ & $209(80.4)$ & $260(100.0)$ & & \\
\hline No & $13(19.1)$ & $55(80.9)$ & $68(100.0)$ & 0.009 & 0.927 \\
\hline \multicolumn{6}{|l|}{$\begin{array}{l}\text { Avoidance of self- } \\
\text { medication }\end{array}$} \\
\hline Yes & $58(20.0)$ & $232(80.0)$ & $290(100.0)$ & & \\
\hline No & $6(16.2)$ & $32(83.8)$ & $38(100.0)$ & 0.379 & 0.538 \\
\hline \multicolumn{6}{|l|}{ Compliance with } \\
\hline \multicolumn{6}{|l|}{ Doctors treatment } \\
\hline Yes & $44(20.3)$ & $173(79.7)$ & $217(100.0)$ & & \\
\hline No & $20(18.0)$ & $91(82.0)$ & $111(100.0)$ & 0.239 & 0.625 \\
\hline \multicolumn{6}{|l|}{$\begin{array}{l}\text { Eye surgeries or } \\
\text { washing with mallam }\end{array}$} \\
\hline Yes & $49(22.0)$ & $174(78.0)$ & $223(100.0)$ & & \\
\hline No & $15(14.3)$ & $90(85.7)$ & $105(100.0)$ & 2.686 & 0.101 \\
\hline
\end{tabular}

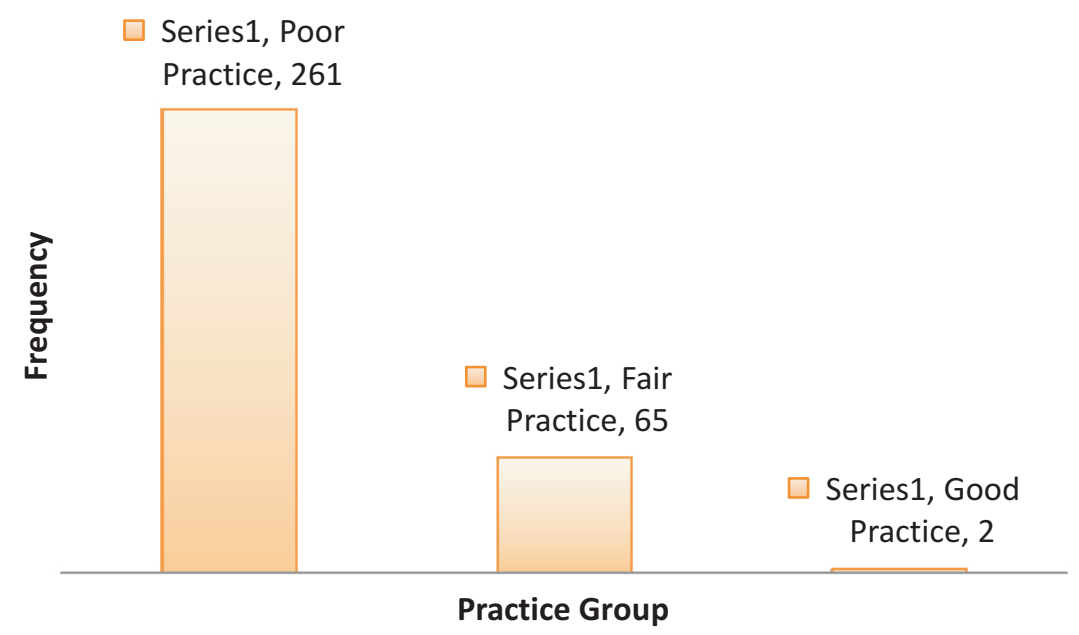

Figure 1: Summary of Respondents' Eye Care Practices 